\title{
Cognitive Behavior Therapy of Urinary Incontinence Phobia: A Case Report
}

\author{
Tina Tan, Leslie Lim \\ Department of Psychiatry, Singapore General Hospital, Republic of Singapore \\ Email: leslie.lim.e.c@sgh.com.sg
}

Received 18 December 2014; accepted 11 January 2015; published 15 January 2015

Copyright (C 2015 by authors and Scientific Research Publishing Inc.

This work is licensed under the Creative Commons Attribution International License (CC BY). http://creativecommons.org/licenses/by/4.0/

(c) (7) Open Access

\begin{abstract}
A significant association exists between lower urinary tract symptoms and anxiety. Despite the efficacy of cognitive behavior therapies in treating a variety of phobic disorders, there are few published reports about the use of such treatments for urinary problems. We report a case of the phobia of urinary incontinence treated with cognitive behavioral techniques, which involved cognitive restructuring, distraction, relaxation training, and exposure to feared situations.
\end{abstract}

\section{Keywords}

Phobia, Urinary Incontinence, Cognitive-Behavior Therapy

\section{Introduction}

It has long been recognised that psychological factors play a substantial role in bladder control [1]. Since the earliest reports by Chertok et al. [2] and Macaulay et al. [3], there are no data confirming the clinical utility of psychological approaches in treating the fear of bladder incontinence. In both studies, patients had physical diagnoses, but improved with psychological treatment. Unfortunately, there were insufficient details about therapy techniques.

It is well established that cognitive behavioral treatment has demonstrated efficacy for a wide variety of psychiatric conditions. In regard to urinary problems, although Hunt sets out the rationale for using cognitive behavior therapy (CBT) for sensory urgency and idiopathic detrusor instability [1], efficacy data have also not been forthcoming.

One of the reasons could be that in the absence of information on successful treatments, there is a paucity of knowledge by clinicians that the utility of CBT could also extend to treating fear of incontinence. As a consequence, once physical causes have been excluded, patients with incontinence phobia tend to be discharged with no referrals made for psychological therapies. 
We report a case of phobia of urinary incontinence successfully treated with CBT.

\section{Case Report}

Ms A was a 39-year-old woman with a 2-year history of a fear of urinary incontinence. She made a self-referral to seek psychiatric help, and had no past medical history of urinary or fecal incontinence.

Her phobia was triggered two years ago during an incident where she had to resist a strong urge to urinate after dinner at a restaurant. Instead, the patient drove for thirty minutes with an uncomfortably full bladder before being able to relieve herself at home. In the background of this incident, she had recently closed down her graphics design company, and had spent several months struggling with bouts of severe anxiety whenever she had to go in to work.

Ms A had a degree in marketing and management. She described her pre-morbid personality as confident, perfectionistic, and high-achieving.

After the precipitating incident, she began to develop a fear of being incontinent. She worried that she would not reach a toilet in time in an unfamiliar and unpredictable situation. This led to certain avoidance behaviors, including her refusal to attend formal events with her husband, because she worried that others might notice her frequent visits to the toilet. She stopped wearing high heels and switched to "flats" so she could more easily make a run for the toilet, if necessary. She also refused to travel overseas for fear of long immigration queues, and also did not drive anywhere alone, or on freeways. She went shopping only in familiar places after memorizing the location of restrooms that were of low-usage. On occasion, when she had to endure unfamiliar situations or places, she would do so with great anxiety and sought constant reassurance from her husband. She would also search for a restroom immediately upon arrival and use it to urinate, before resuming her intended activities.

At its most severe, her phobia caused her to experience urinary urges every 10 - 15 minutes, despite having already gone to the restroom. Telling herself that her fear was irrational only achieved partial results. In contrast, she was able to sleep through the night without any incontinence issues, and only required the toilet every 2 - 3 hours when at home.

Ms A was diagnosed with a specific phobia of urinary incontinence. It was decided to treat her condition using a cognitive behavioral approach, without the use of pharmacotherapy. She was treated over a course of seven sessions. We present a summary of the techniques used and a discussion of her progress.

\section{Description of Therapy}

During the first session, the therapist took a history of Ms A's problems. She was given an explanation of CBT, and socialized to the rationale of the treatment and what was expected of her during, and in between therapy sessions. She was taught how to record her negative thoughts in a Daily Thought Record (DTR) form. Ms A's husband, who attended the session with her (as well as all subsequent sessions) volunteered to serve as a role model for normal behavior.

Her homework assignments at the end of this session were to make urine measurements. One of the assignments included measuring her urine upon waking from sleep the first thing in the morning. This important data would serve to illustrate how much urine her bladder could hold during the night. She was also instructed to record her negative thoughts in relation to anxiety-inducing cues, for example, driving to a shopping center.

In Session 2, Ms A handed in her assignments. Her urine measurements are shown in Table 1. The homework assignment served to confirm to her that she was physically able to hold a substantial volume of urine (highest recorded volume of $750 \mathrm{~mL}$ ) for a sustained duration of time (highest recorded duration of 7.25 hours).

Using Socratic questioning during the session, the therapist encouraged Ms A to think of rational statements to counter her phobic negative automatic thoughts (NATs). For example, concerning the NAT "cannot hold my urine while waiting," she was able to rationalize that she had only waited for 10 - 15 minutes and need not have worried. She realized that since she had, during sleep, been able to hold her urine for at least 7 hours, there was no risk of her becoming incontinent over shorter periods during the day.

Ms A was educated on the importance of exposure in order to achieve habituation of anxiety. She was asked to continue her urine measurements as homework. Ms A also agreed to conduct a behavioral experiment to refrain from using the toilet for at least 30 minutes after arriving at a destination.

In Session 3, Ms A reported that she was able to drive on her own to an unfamiliar location for dinner and not 
Table 1. Quantity of urine (mL) and duration of time (hr) since last urination.

\begin{tabular}{cccc}
\hline Date & Time of urination $(\mathrm{hr})$ & Duration since last urination $(\mathrm{hr})$ & Quantity of urine produced $(\mathrm{mL})$ \\
\hline 21 May & $23: 55$ & 2.25 & 300 \\
22 May & $10: 30$ & 7.25 & 500 \\
22 May & $13: 15$ & 1.50 & 650 \\
22 May & $23: 40$ & 2.00 & 600 \\
23 May & $01: 35$ & 2.00 & 250 \\
23 May & $11: 15$ & 7.00 & 450 \\
23 May & $16: 15$ & 1.75 & 750 \\
31 May & $16: 55$ & 2.00 & 650 \\
31 May & $18: 55$ & 2.00 & 550 \\
\hline
\end{tabular}

visit the restroom for 30 minutes. She admitted to being slightly worried during the drive, but managed to overcome her fears with deep breathing, and the use of positive self-statements, e.g. "I achieved bladder control for 7 hours. I can do this again.”

She was given another homework experiment, which was to drive herself to various destinations, rate her subjective sense of anxiety, and refrain from using the restroom for at least 40 minutes upon arrival. Ms A's husband was initially instructed to accompany her on her exposure assignments but subsequently, as she mastered her tasks, was asked to let her enter the anxiety-provoking situations alone.

Exploration into the trigger for Ms A's problems revealed that Ms A had some cognitive distortions that were related to her business failure two years ago, and this had some impact on her current symptoms. She described herself as a "failure" because of the closure of her business, and over-generalized her failure at business to failure of herself as a person, and in part because she was also suffering from a psychiatric problem. She had a tendency to maximize these negative aspects of her life, and minimize her past and current successes (for example, her career before the business failure, her successful marriage, and her rapid progress in treatment). Once Ms A recognized these cognitive distortions, she was encouraged to view her achievements and setbacks with a more balanced perspective.

In Sessions 4 and 5, Ms A completed her assignment to rate her anxiety in various situations. Table 2 lists a sample of her activities, which showed improvement in her self-reported anxiety scores as therapy progressed. She was encouraged to use such self-statements as, "I've done this before and successfully held my urine" to counter her anxiety.

As part of her homework in session 4, Ms A was asked to prepare a hierarchy of feared situations for the purpose of exposure-habituation exercises. The hierarchy is appended in Table 3. Given that Ms A had already begun to expose herself to situations lower in the hierarchy, it was decided to focus on items higher up the hierarchy, such as driving alone and sitting through hair salon appointments. This was her homework assignment for sessions 5 and 6. Ms A was also asked to do variations of the feared situations, such as driving to different locations over increasing distances alone, and not use the restroom for 50 minutes upon arrival at the destination.

By session 6, Ms A reported that she was able to confront a wide variety of situations on the hierarchy and that she had successfully kept her urine for 60 minutes. To help overcome her anticipatory anxiety, she was able to distract herself by talking to her husband until she felt calmer.

Without prior discussion with the therapist, she reported that she had booked plane tickets for an overseas trip with her husband. She listed several feared situations that she might encounter during her travels, including immigration queues, making road trips, and having to walk around in an unfamiliar city. The therapist encouraged her to imagine being in various situations in the course of her travel. She responded positively to imaginal exposure and reported a lessening of anxiety at the end of the exercise. She was given the homework assignment to continue mentally rehearsing different scenarios of her trip so she could be prepared for the actual journey.

Ms A was also praised for her success with bladder control, and was encouraged to continue practicing bladder control for at least 60 minutes at a time. 
Table 2. Type of daily activities with anxiety scores. Key: 0 - no anxiety; 5 - extreme anxiety.

\begin{tabular}{|ccc}
\hline Activity & $\begin{array}{c}\text { Anxiety score prior to } \\
\text { treatment }\end{array}$ & $\begin{array}{c}\text { Anxiety score with } \\
\text { treatment }\end{array}$ \\
\hline Driving to and from a popular shopping outlet, including parking time & 3.5 & 0 \\
Driving to mother's house & 3.5 & 4 \\
Driving home from mother's house & 4 & 0 \\
Driving to the hospital for therapy & 3 & 0 \\
Walking to and from nearby shops & & 2 \\
\hline
\end{tabular}

$\begin{array}{cc}\begin{array}{c}\text { Table 3. Hierarchy of Ms A's feared situations, ranked from least feared (10) to most feared (1). } \\ 2\end{array} & \begin{array}{c}\text { Traveling around an unfamiliar overseas destination alone. } \\ 3\end{array} \\ 4 & \text { Queuing up for immigration clearance alone. } \\ 5 & \text { Sitting through a massage or visiting a hair salon } \\ 6 & \text { (because the masseuse/hairstylist would notice if she excused herself to the toilet). } \\ 7 & \text { Riding in the car with husband driving on highways. } \\ 8 & \text { Riding in the car with husband driving on local streets. } \\ 9 & \text { Taking public transport into town. } \\ 10 & \text { Taking } 20 \text { minute walks to a familiar shopping mall. }\end{array}$

In the final session, she reported overall improvement in her phobia of urinary incontinence. She had reduced the urge to head for a restroom upon arrival at a destination for 60 minutes. She was able to drive on highways alone for one and a half hours and also felt more relaxed, in general.

Though she harbored residual anxieties pertaining to her overseas trip, she felt confident that she would be able to travel without major issues. She was able to summarize the main learning points in her therapy and wrote these down in a note book for future reference.

On follow up review, her first overseas trip in two years was a success. She continued to do well, using the techniques that she had learned in therapy.

\section{Discussion}

The behavioral task of delaying bladder emptying over progressively longer time intervals served as exposure to the feared situation of bladder incontinence. The important lesson she learned from urine measurement (a lessthan-pleasant assignment) was that her bladder capacity was more than sufficient for her to cope with different situations with increasing periods of delay in onset of micturition. Through questioning her negative cognitions she realized that her fears were without basis. This served to motivate her to perform exposure-based homework assignments.

Success of the therapy hinged upon several factors: her motivation to overcome her phobia and exposure to the feared situations. The latter tasks provided objective information of the ability of her bladder to contain increasing amounts of urine without any danger of incontinence. Exposure to fear-inducing situations e.g. driving along the highway, visiting shopping malls while delaying seeking restrooms allowed her anxiety to habituate, but cognitively also served to reinforce the message that she was able to maintain bladder control in these situations better than she thought she could. The use of distraction and relaxation exercises was meant to facilitate her ability to perform her homework exposure exercises in the initial stages of treatment. By the 3rd session, with mastery over her phobia becoming evident, she was encouraged to practice her exposure exercises without 
resorting to distraction techniques. She was also encouraged to drive to various destinations alone, gradually increasing the distances covered.

The incentive to get better was the real possibility of being able to go on holiday with her husband. Owing to the impracticality of familiarizing herself with the location of restrooms in a foreign country, Ms A was encouraged to deal with these fears through the use of imaginal exposure i.e. arriving at a foreign airport and queuing up at the immigration counter without knowing the location of the restroom. Here the lessons learned about her abilities to hold her urine proved useful. Although the results of imaginal exposure are less impressive as those of exposure in vivo [4], nevertheless the use of this technique was inevitable as there was no other better choice in this case.

Relaxation exercises do not appear to benefit patients with phobias [5]. By contrast, the efficacy of exposure therapy has been well established [4]-[6]. Although it was initially held that exposure was key to anxiety reduction [5], more recent randomized control trials (RCTs) have demonstrated fear reduction in the course of cognitive therapy for various anxiety conditions [7]-[9]. In the latter RCTs, behavioral experiments and exposure instructions were excluded from therapy. This begs the usual questions about the ingredients of successful therapy, with suggestions that a sense of control, and uncoupling thoughts and feelings from one's behavioral reactions could ultimately prove therapeutic [10].

\section{Conclusions}

Cognitive behavior therapy is a well-established treatment of specific phobias [6]. Although treatment has been adapted to target a wide variety of phobic conditions [11]-[14], the literature is sparse on treatment success with the phobia of urinary incontinence. However, significant association has been found between lower urinary tract symptoms and anxiety [1] [3] [15] [16]. In this case report, we have illustrated use of CBT techniques to overcome phobia of urinary incontinence. Treatment involved using cognitive restructuring, distraction, relaxation training and exposure to feared situations carried out as homework assignments. It involved increasing distances of travel from home with prohibition on urination for increasing periods of time.

This single case report has its limitations, given the short duration of treatment and follow up, and the absence of validated rating scales, although the intensity of anxiety was subjectively rated. It is hoped that the successful use of these techniques may encourage randomized controlled trials with larger numbers of patients with efficacy outcomes rated over the short- and long-term.

\section{References}

[1] Hunt, J. (1996) Psychological Approaches to the Management of Sensory Urgency and Idiopathic Detrusor Instability. British Journal of Urology, 77, 339-341. http://dx.doi.org/10.1046/j.1464-410X.1996.08992.x

[2] Chertok, L., Bouruignon, O., Guillon, F. and Aboulker, P. (1997) Urethral Syndrome in the Female (Irritable Bladder): The Expression of Fantasies about the Urogenital Area. Psychosomatic Medicine, 39, 110.

[3] Macaulay, A.J., Stern, R.S. and Stanton, S.L. (1991) Psychological Aspects of 211 Female Patients Attending a Urodynamic Unit. Journal of Psychosomatic Research, 35, 1-10. http://dx.doi.org/10.1016/0022-3999(91)90002-6

[4] Marks, I.M., Swinson, R.P., Başoğlu, M., Kuch, K., Noshirvani, H., O’Sullivan, G., Lelliott, P.T., Kirby, M., McNamee, G., Sengun, S., et al. (1993) Alprazolam and Exposure Alone and Combined in Panic Disorder with Agoraphobia. A Controlled Study in London and Toronto. British Journal of Psychiatry, 162, 776-787. http://dx.doi.org/10.1192/bjp.162.6.776

[5] Marks, I.M. (1987) Fears, Phobias and Rituals: Panic, Anxiety, and Their Disorders. Oxford University Press, Oxford.

[6] Wolitzky-Taylor, K.B., Horowitz, J.D., Powers, M.B. and Telch, M.J. (2008) Psychological Approaches in the Treatment of Specific Phobias: A Meta-Analysis. Clinical Psychology Review, 28, 1021-1037. http://dx.doi.org/10.1016/j.cpr.2008.02.007

[7] Ost, I., Fellenius, J. and Sterner, U. (1991) Applied Tension, Exposure in Vivo, and Tension-Only in the Treatment of Blood Phobia. Behavioral Research and Therapy, 29, 561-574. http://dx.doi.org/10.1016/0005-7967(91)90006-O

[8] van Oppen, P., de Haan, F., van Balkom, A.J., Spinhoven, P., Hoogquin, K. and van Dyck, R. (1995) Cognitive Therapy and Exposure in Vivo in the Treatment of Obsessive Compulsive Disorder. Behavioral Research and Therapy, 33, 379-390. http://dx.doi.org/10.1016/0005-7967(94)00052-L

[9] Tarrier, N., Sommerfield, C., Pilgrim, H. and Humphreys, L. (1999) Cognitive Therapy or Imaginal Exposure in the Treatment of Post-Traumatic Stress Disorder. Twelve-Month Follow-Up. British Journal of Psychiatry, 175, 571-575. http://dx.doi.org/10.1192/bjp.175.6.571 
[10] Marks, I. and Dar, R. (2000) Fear Reduction by Psychotherapies. Recent Findings, Future Directions. British Journal of Psychiatry, 176, 507-511. http://dx.doi.org/10.1192/bjp.176.6.507

[11] Ponniah, K. and Hollon, S.D. (2008) Empirically Supported Psychological Interventions for Social Phobia: A Qualitative Review of Randomized Controlled Trials. Psychological Medicine, 38, 3-14. http://dx.doi.org/10.1017/S0033291707000918

[12] Maack, D.J., Deacon, B.J. and Zhao, M. (2013) Exposure Therapy for Ematophobia: A Case Study with Three-Year Follow-Up. Journal of Anxiety Disorders, 27, 527-534. http://dx.doi.org/10.1016/j.janxdis.2013.07.001

[13] McDonnell-Boudra, D., Martin, A. and Hussein, I. (2014) In Vivo Exposure Therapy for the Treatment of an Adult Needle Phobic. Dental Update, 41, 533-536,539-540.

[14] Coelho, C.M., Waters, A.M., Hine, T.J. and Wallis, G. (2009) The Use of Virtual Reality in Acrophobia Research and Treatment. Journal of Anxiety Disorders, 23, 563-574. http://dx.doi.org/10.1016/j.janxdis.2009.01.014

[15] Coyne, K.S., Wein, A.J., Tubaro, A., Sexton, C.C., Thompson, C.L., Kopp, Z.S. and Aiyer, L.P. (2009) The Burden of Lower Urinary Tract Symptoms: Evaluating the Effect of LUTS on Health-Related Quality of Life, Anxiety and Depression: EpiLUTS. British Journal of Urology International, 103, 4-11. http://dx.doi.org/10.1111/j.1464-410X.2009.08371.x

[16] Bogner, H.R., O’Donnell, A.J., de Vries, H.F., Northington, G.M. and Joo, J.H. (2011) The Temporal Relationship between Anxiety Disorders and Urinary Incontinence among Community-Dwelling Adults. Journal of Anxiety Disorders, 25, 203-208. http://dx.doi.org/10.1016/j.janxdis.2010.09.003 
Scientific Research Publishing (SCIRP) is one of the largest Open Access journal publishers. It is currently publishing more than 200 open access, online, peer-reviewed journals covering a wide range of academic disciplines. SCIRP serves the worldwide academic communities and contributes to the progress and application of science with its publication.

Other selected journals from SCIRP are listed as below. Submit your manuscript to us via either submit@scirp.org or Online Submission Portal.
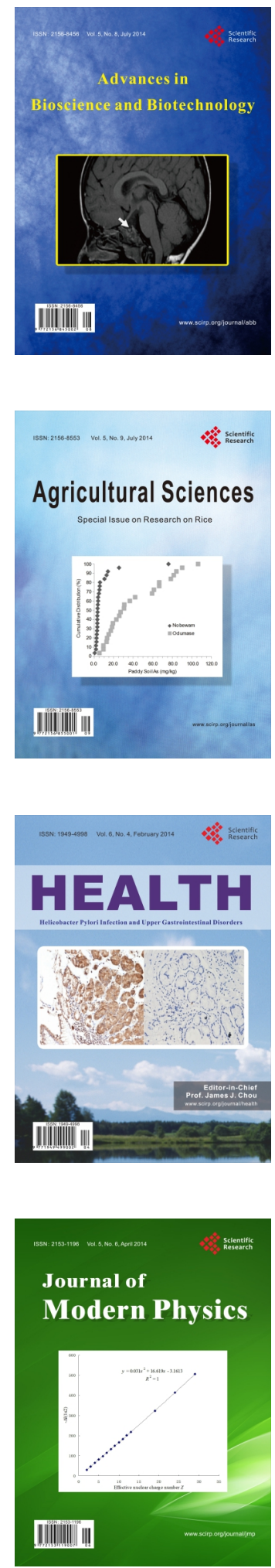
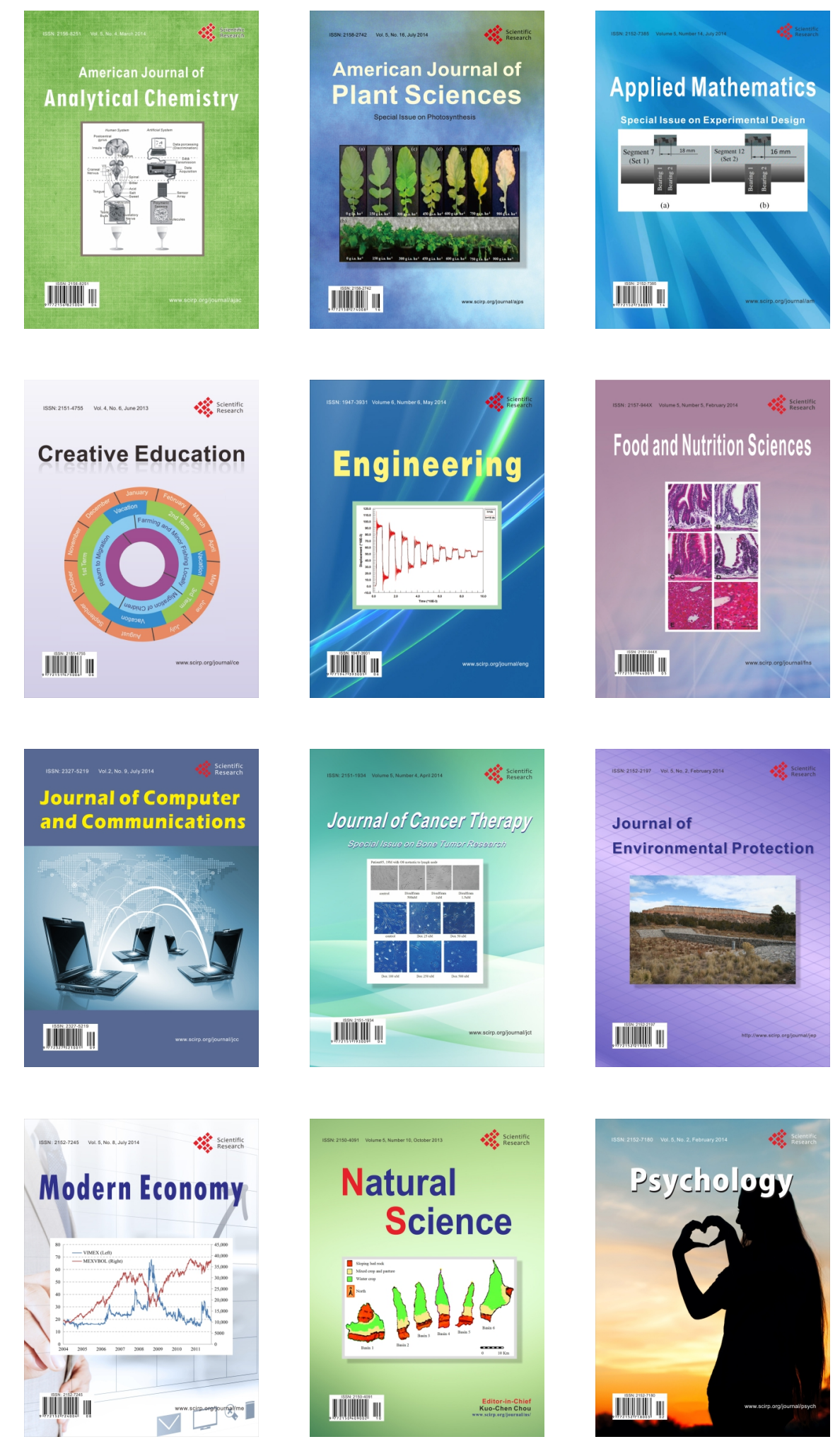